\title{
Fabrication of aluminum matrix composites reinforced with nano- to micrometer-sized SiC particles
}

\author{
R. Taherzadeh Mousavian ${ }^{\text {a }}$, R. Azari Khosroshahi ${ }^{\mathrm{a}} \square$, , S. Yazdani ${ }^{\text {a }}$, D. Brabazon ${ }^{\mathrm{b}}$, A.F. Boostani ${ }^{\mathrm{c}}$ \\ ${ }^{a}$ Faculty of Materials Engineering, Sahand University of Technology, Tabriz, Iran \\ ${ }^{\mathrm{b}}$ Advanced Processing Technology Research Centre, School of Mechanical \& Manufacturing Engineering, Dublin City University, Dublin 9, Ireland \\ ${ }^{\mathrm{c}}$ School of Mechanical, Materials and Mechatronic Engineering, University of Wollongong, NSW 2522, Australia
}

Keywords:

Aluminum matrix composite Ball milling, Casting Extrusion

\begin{abstract}
In this study, the hot extrusion process was applied to stir cast aluminum matrix-SiC composites in order to im- prove their microstructure and reduce cast part defects. $\mathrm{SiC}$ particles were ball milled with $\mathrm{Cr}, \mathrm{Cu}$, and $\mathrm{Ti}$ as three forms of carrier agents to improve $\mathrm{SiC}$ incorporation. Large brittle ceramic particles (average particle size: $80 \mu \mathrm{m}$ ) were fragmented during ball-milling to form nanoparticles in order to reduce the cost of composite manufactur- ing. The experimental results indicate that full conversion of coarse micron sized to nanoparticles, even after $36 \mathrm{~h}$ of ball milling, was not possible. Multi modal SiC particle size distributions which included $\mathrm{SiC}$ nanoparticles were produced after the milling process, leading to the incorporation of a size range of SiC particle sizes from about $50 \mathrm{~nm}$ to larger than $10 \mu \mathrm{m}$, into the molten A356 aluminum alloy. The particle size of the milled powders and the amount of released heat from the reaction between the carrier agent and molten aluminum are inferred as two crucial factors that affect the resultant part tensile properties and microhardness.
\end{abstract}

\section{Introduction}

The use of Al-Si (in particular A356) alloys in the manufacture of au- tomotive engine components has increased considerably in recent years [1-6]. Although high-strength aluminum alloys have been developed, the addition of alloying elements and microstructural modification, can be costly, contain toxic elements, and often results in properties, which only result in a slight increase in stiffness. The demands for lightweight, highmodulus, and high-strength materials have therefore led to the development of aluminum matrix nanocomposites (AMNCs) [2,7-18].

Various methods have been developed for the production of metal- matrix composites. An economical way of producing metal-matrix composites is the incorporation of the particles into the liquid or semi-solid metal and casting [19-22]. Semi-solid stir casting process transforms from dendritic to globular the phase structure such that fine ceramic particles can be mechanically trapped in within a highly viscous aluminum melt $[23,24]$.

A good distribution of micron-particles was obtained in our previous studies by using various wettability improvement methods such as interfacial-active element addition by ball milling of ceramic powders with $\mathrm{Al}$ and $\mathrm{Mg}$ powders [19] and electroless deposition of $\mathrm{Ni}-\mathrm{P}$ [25], $\mathrm{Cu}[26]$, and $\mathrm{Co}[27,28]$ on the ceramics. In these cases, improved strength and hardness were obtained for the micron-SiC $\mathrm{p} / \mathrm{Al}$ composites compared with the unreinforced $\mathrm{Al}$ alloys, while a signifi- cantly reduced ductility limits their widespread application. It is of in- terest to use $\mathrm{SiC}$ nanoparticles to improve the strength and hardness of the matrix, while maintaining good ductility at room temperature $[8,10]$. However, due to their large surface-to-volume ratio, attractive van der Waals interactions, and poor wettability of fine ceramic parti- cles by molten aluminum, achievement of their uniform dispersion is not an easy task [7,10,22].

Su et al. [29] suggested an idea, in which nanosized particles could be uniformly dispersed on the surface of a carrier using ball milling process. They used aluminum powders as the carrier agent. Nanoparticle engulf- ment could be achieved during solidification via various methods such as increasing the thermal conductivity of ceramics [30-32], using graphene encapsulated nanoparticles [7], and rapid solidification [33]. A significant problem that has not yet received sufficient attention is that the as-received nanoparticles are in the agglomerated form before casting. Therefore, the idea of carrier agent has two important advan- tages; first, it could prevent the nanoparticles from agglomeration due to their possible capturing by a layer of carrier agent and secondly, the presence of carrier agent could be used to increase the wettability of the ceramic by molten aluminum. The carrier agent efficiency could therefore be enhanced by:

- Utilizing a high density of carrier agent.

- Utilizing a carrier agent which has a reasonable life time within the melt such that it would not be immediately lost by entering at the vortex (for this purpose, it must have a higher melting temperature than aluminum). In fact, immediate and simultaneous releasing of fine particles would lead to formation of severe clusters during stirring.

- Providing as low release of the nanoparticles into the molten metal to allow them make a suitable bond with the matrix.

The idea of using large micron reinforcement particles and their conversion to nanoparticles by fracturing during the ball milling process is a cost-effective approach. A higher wettability may be simul- taneously achieved the micron particles are milled with a carrier agent. 

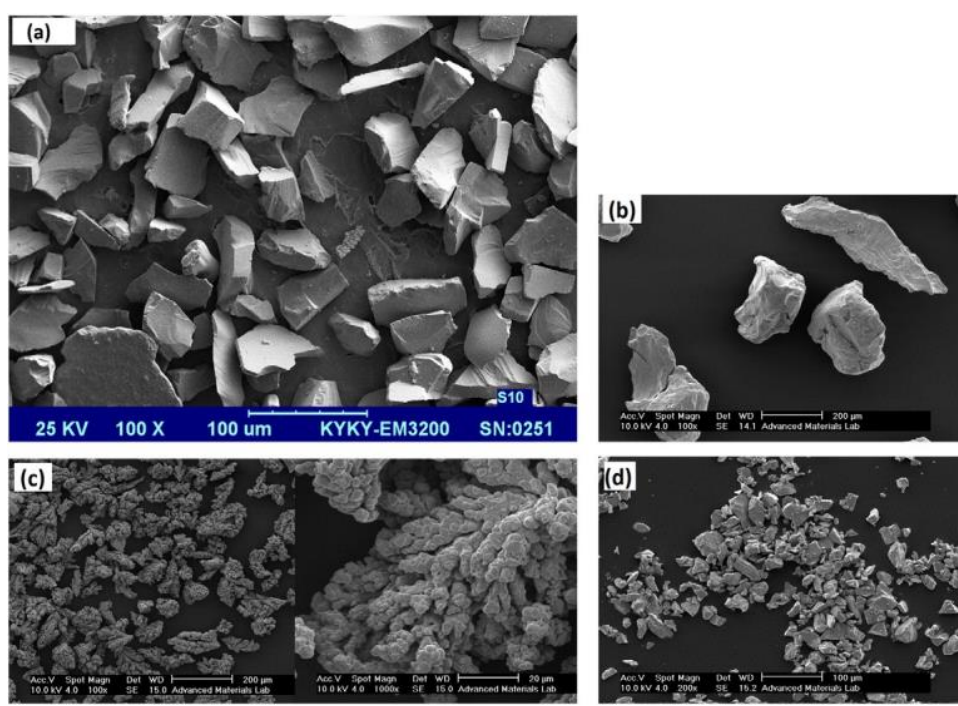

Fig. 1. SEM morphology of (a) $\mathrm{SiC}$, and (b) $\mathrm{Cr}$, (c) $\mathrm{Cu}$, and (d) Ti powders.

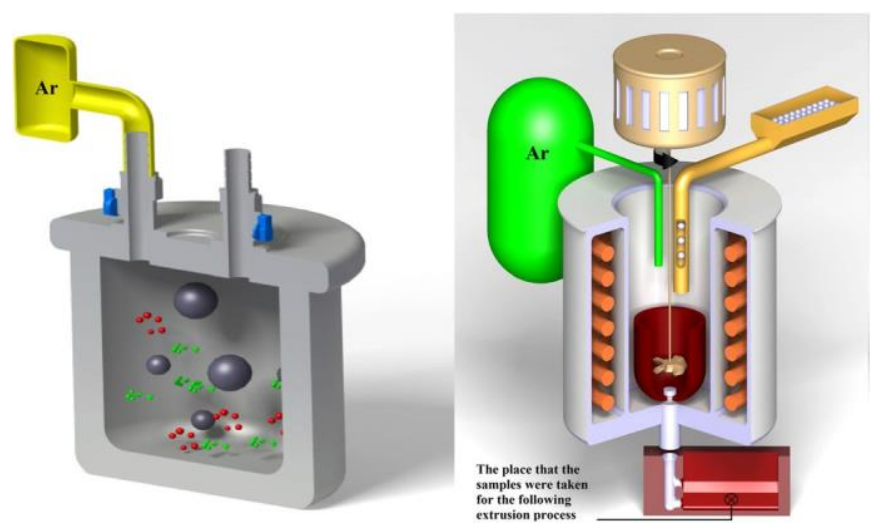

Fig. 2. Schematic of (a) ball-mill vial equipped with argon atmosphere and (b) stir-casting set-up.

In this study, large micron $\mathrm{SiC}$ particles were ball milled with three kinds of carrier agents $(\mathrm{Ti}, \mathrm{Cr}$, and $\mathrm{Cu}$ ) to produce nanocomposite superstructures [34] before incorporation into the molten A356 aluminum alloy. Semi-solid stir casting followed by the hot extrusion process were then applied for AMNCs manufacturing to ensure a lower porosity content, a better interfacial bonding between particle and matrix, possi- ble separation of agglomerated particles, and refinement of the matrix structure.

\section{Experimental procedure}

A356 ingot was used as a matrix aluminum alloy. Table 1 presents the chemical composition of the ingot used in this work as obtained using a M5000 optical emission spectrometer, Focused Photonics Inc., China.

Fig. 1a shows the morphology of as-received $\mathrm{SiC}$ particles with an av- erage particle size of $80 \mu \mathrm{m}$ and $99.9 \%$ purity as well as those of pure $\mathrm{Cr}$ (99.1\% purity, Fig. 1b), Cu (98.9\% purity, Fig. 1c), and Ti (99.0\% purity, Fig. 1d) carrier agents that were supplied from Shanghai Dinghan Chemical Co., Ltd. China. It could be seen that in contrast with $\mathrm{Cr}$ pow- ders that were coarse in particle size, both the $\mathrm{Cu}$ and $\mathrm{Ti}$ powders have an average particle size below $20 \mu \mathrm{m}$.

Table 1

The chemical composition (in wt.\%) of A356 aluminum alloy used in this study.

\begin{tabular}{lllllllll}
\hline $\mathrm{Al} \%$ & $\mathrm{Si} \%$ & $\mathrm{Mg} \%$ & $\mathrm{Fe} \%$ & $\mathrm{Cu} \%$ & $\mathrm{Mn} \%$ & $\mathrm{Zn} \%$ & $\mathrm{Ni} \%$ & $\mathrm{Ti} \%$ \\
\hline Bal. & 7.2 & 0.33 & 0.11 & 0.01 & 0.02 & 0.02 & 0.03 & 0.01 \\
\hline
\end{tabular}

Based on the idea suggested by Su et.al [29], three samples were fab- ricated in this study, containing ball-milled $\mathrm{Cr}-\mathrm{SiC}, \mathrm{Cu}-\mathrm{SiC}$, and Ti-SiC powders. These samples were produced with $15 \mathrm{~g}$ of $\mathrm{SiC}$ and $10 \mathrm{~g}$ of car- rier metals, which were $\mathrm{Cr}\left(\mathrm{S}_{1}\right), \mathrm{Cu}\left(\mathrm{S}_{2}\right)$, and Ti $\left(\mathrm{S}_{3}\right)$ for this study. The ball-milling process was performed in this study by using a planetary ball mill (Sepahan 84D) with steel vial and a blend of hardened steel balls (10 $\mathrm{mm}$ and $20 \mathrm{~mm}$ diameters) in argon atmosphere. Xu et al. [34] suggested that four types of nanocomposite superstructures (Alcore/nanoparticle-shell superstructure, nanocomposite-core/ nanoparticle-shell superstructure, metal-linked core/shell nanostruc- tures, 
and metal-linked nanoparticles) could be formed after mixing nanoparticles with aluminum powders. The milling process was there- fore applied for 1, 12, 24, and $36 \mathrm{~h}$ using $1 \mathrm{wt} . \%$ stearic acid as process control agent (PCA) to evaluate the conversion of coarse SiC powders to fine particles as well as study on the prepared nanocomposite super- structures by increasing the milling time. These powders were incorpo- rated into the molten A356 aluminum to fabricate AMNCs reinforced with 3 wt. \% SiC and 2 wt. \% carrier agents. For this purpose, one gram of the reinforcement powders was encapsulated carefully in an alumi- num foil packet before the stir casting process. These packets were then pre-heated at $300{ }^{\circ} \mathrm{C}$ for $1 \mathrm{~h}$ in order to remove the moisture and impurities from the powders. The A356 alloy $(475 \pm 5 \mathrm{~g})$ was heated to 640 ${ }^{\circ} \mathrm{C}$ using a resistance furnace in order to have uniform melt con- dition. The melt was then cooled to $600{ }^{\circ} \mathrm{C}$ corresponding to a 0.3 solid fraction, based on analysis with Thermo-Calc software which was shown in our previous study [2].

$\mathrm{A} \mathrm{ZrO}_{2}$ coated-stainless steel stirrer was placed below the surface of melt, rotated with a speed of $500 \mathrm{rpm}$, while high purity argon gas was simultaneously applied as a protective shroud on the melt surface. Dur- ing the stir-casting process, the aluminum foil packets were added to the vortex center at $600^{\circ} \mathrm{C}$ during the first minute of the semi-solid stir- ring. The temperature of the melt was then increased to $630{ }^{\circ} \mathrm{C}$, which is above the melting point of A356 alloy, and the stirring was continued for another $5 \mathrm{~min}$. An addition of $1 \mathrm{wt} \% \mathrm{Mg}$ was also added during the reinforcement feeding process, to improve the reinforcement wetta- bility by molten metal. The composite slurry in the liquid state was poured into a low-carbon steel mold (at $25{ }^{\circ} \mathrm{C}$ ). A schematic of the ball-milling process as well as the stir-casting set-up and its bottom- pouring system was shown in detail in Fig. 2. This figure also shows the central location from which the samples were taken from the com- posite casting for machining before the extrusion process and subse- quent characterization.

Disk-shape samples with $27 \mathrm{~mm}$ diameter were machined from the solidified composites for the extrusion specimens. The composite billets were then extruded to $9 \mathrm{~mm}$ diameter bars, through shear-faced dies, with a speed of $0.2 \mathrm{~mm} \mathrm{~s}^{-1}$. Table 2 shows the other parameters of the hot extrusion process. The tensile tests were performed at room temperature usinganuniaxialtensile INSTRON(Model5982), USA, universal testing machine of $100 \mathrm{kN}$ operating at a constant rate of cross- head displacement, with an initial strain rate of $2 \times 10-3 \mathrm{~s}^{-1}$. The YS (yield strength), UTS (ultimate tensile strength), and ductility (percent elongation to break) were measured and averaged over three test samples. The dog-bone-shaped tensile specimens had a gauge size of $4 \mathrm{~mm}$ in diameter and $24 \mathrm{~mm}$ in length, according to ASTMB557M-10.

Microhardness testing was conducted according to ASTM E384 using an applied load of $100 \mathrm{~g}$ for a $15 \mathrm{~s}$ duration. At least ten measurements were taken from the as-cast and extruded samples. Microstruc- tural characterizations were performed using two kinds of scanning electron microscopes (SEM, KYKY-EM3200 and SEM, Philips XL 30, equipped with EDAX analysis), a field emission scanning electron mi- croscopy (FESEM-Mira Tescan), and an optical microscopy (OM, Olym- pus equipped with digital camera model DP73). For this

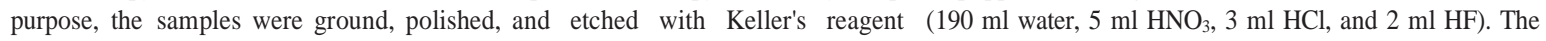
average porosity contents of the produced samples in as-cast and extruded conditions were determined using the Archimedean method. The phase composi- tions of the $36 \mathrm{~h}$ ball milled powders were characterized by using X- ray diffractometer (Bruker's D8 advance system, Germany) using $\mathrm{Cu} \mathrm{K \alpha}(\lambda=0.15405 \mathrm{~nm})$ radiation to indicate if any reaction between SiC powders and the carrier agents had taken place during the $36 \mathrm{~h}$ mill- ing process.

Table 2

Characteristics of the samples fabricated in this study.

\begin{tabular}{lllllll}
\hline Samples & Ball milling time $(\mathrm{h})$ & Ball milling speed $(\mathrm{rpm})$ & Ball to powder weight ratio & Stir casting time $(\mathrm{min})$ & Reduction ratio for extrusion & Extrusion temperature $\left({ }^{\circ} \mathrm{C}\right)$ \\
\hline $\mathrm{S}_{1}$ & 36 & 220 & $8: 1$ & 6 & $9: 1$ & 500 \\
$\mathrm{~S}_{2}$ & 36 & 220 & $8: 1$ & 6 & $9: 1$ & 500 \\
$\mathrm{~S}_{3}$ & 36 & 220 & $8: 1$ & 6 & $9: 1$ & 500 \\
\hline
\end{tabular}

\section{Results and discussion}

As noted, the ball-milling process was used in this study for two pur- poses, firstly to prepare fine $\mathrm{SiC}$ powders from large micron sized $\mathrm{SiC}$ particles and secondly to aid incorporation of fine ceramic particles. Therefore, the micron sized SiC particles were ball milled with the three metal carrier agents for 1, 12, 24, and $36 \mathrm{~h}$ to study the progress of SiC fragmentation as well as possible formation of nanocomposite superstructures. Fig. 3a shows the morphology of $\mathrm{Cr}-\mathrm{SiC}$ mixture after $1 \mathrm{~h}$ of ball milling. Large sized $\mathrm{SiC}$ articles with relatively sharp edges could be seen in the low-magnification image (left-hand image) of Fig. 3a. A considerable amount of small particles were detected and marked by red-colored rectangles, showing the effect of milling process on frag- mentation of the ceramic particles. The right-hand image with a higher magnification shows the surface of a large $\mathrm{SiC}$ particle that our EDAX analysis detected the presence of $\mathrm{Cr}$ element on this surface. As it can be seen, some small $\mathrm{SiC}$ particles with a particle size from $300 \mathrm{~nm}$ to about $3 \mu \mathrm{m}$ were embedded on these large $\mathrm{Cr}$-coated $\mathrm{SiC}$ particles. A schematic of a large $\mathrm{Cr}$-coated $\mathrm{SiC}$ particles with the presence of small fragmented $\mathrm{SiC}$ particles on its surface is presented in the right-hand image to indicate the prepared structure after $1 \mathrm{~h}$ of ball-milling. 

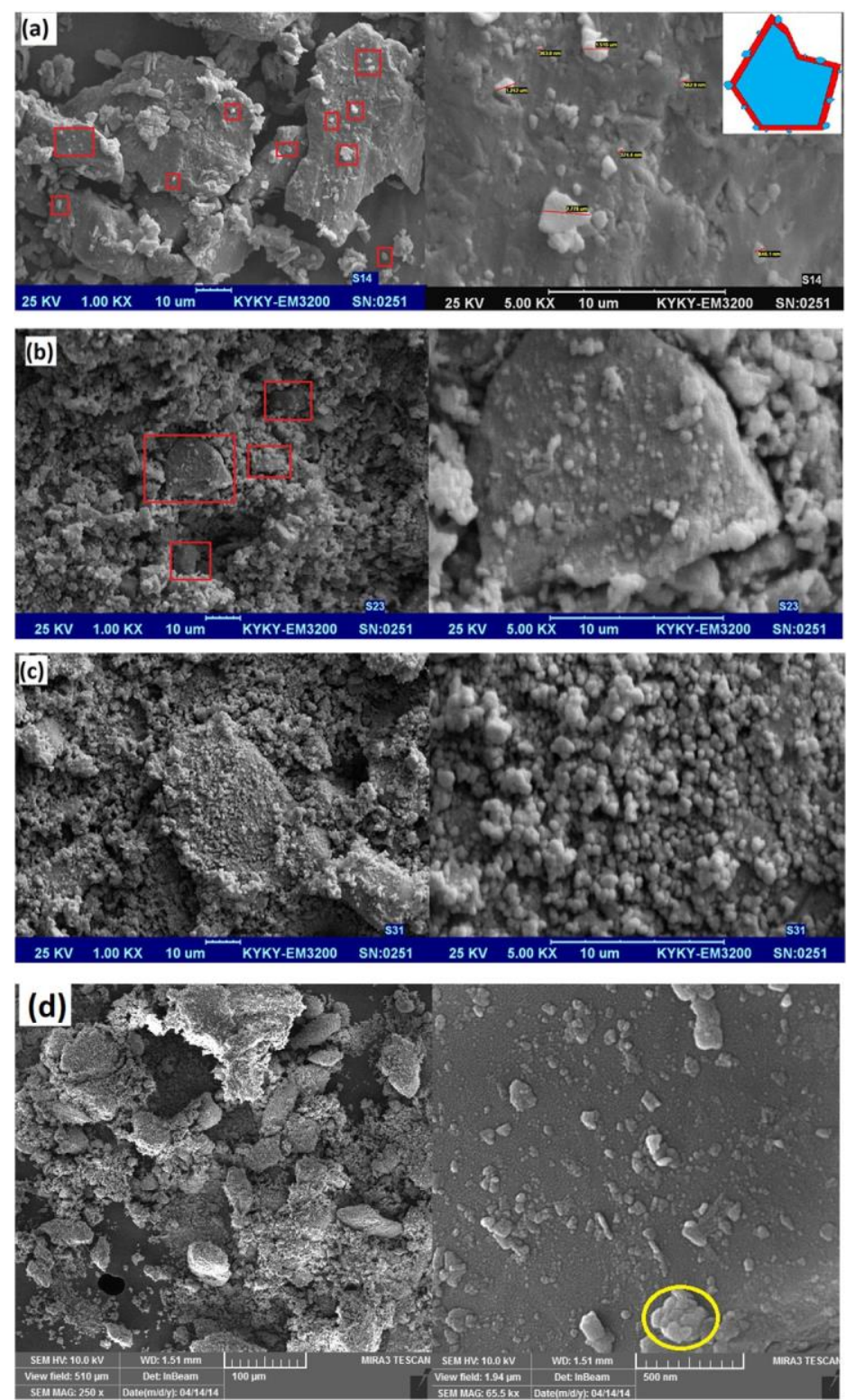

Fig. 3. The morphology of Cr-SiC powder mixture after $1 \mathrm{~h} \mathrm{(a),} 12 \mathrm{~h}$ (b), $24 \mathrm{~h}$ (c), and $36 \mathrm{~h}$ (d) of ball milling process 

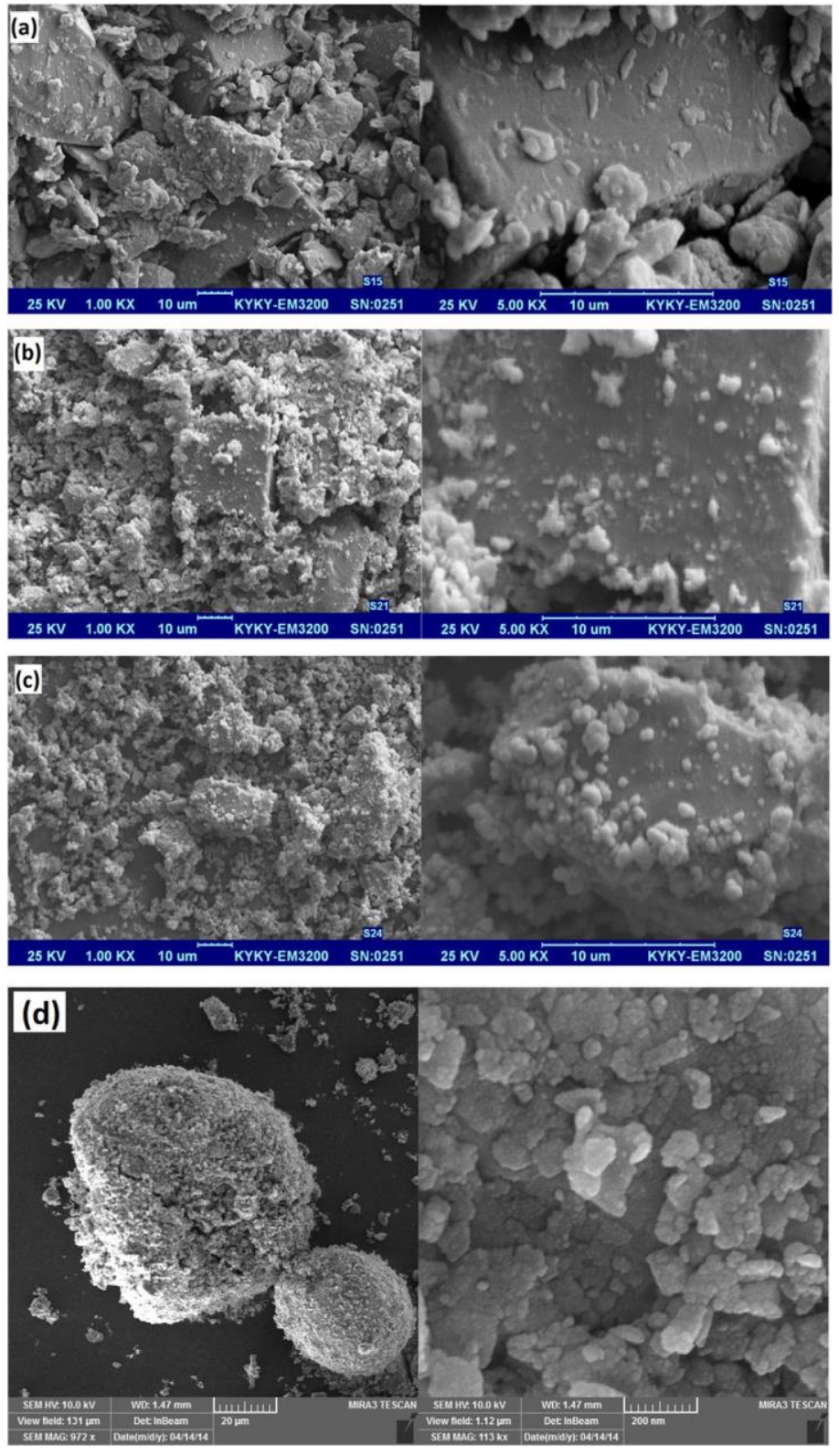

Fig. 4. The morphology of Cu-SiC powder mixture after $1 \mathrm{~h} \mathrm{(a),} 12 \mathrm{~h}$ (b), $24 \mathrm{~h}$ (c), and $36 \mathrm{~h}$ (d) of ball milling process. 

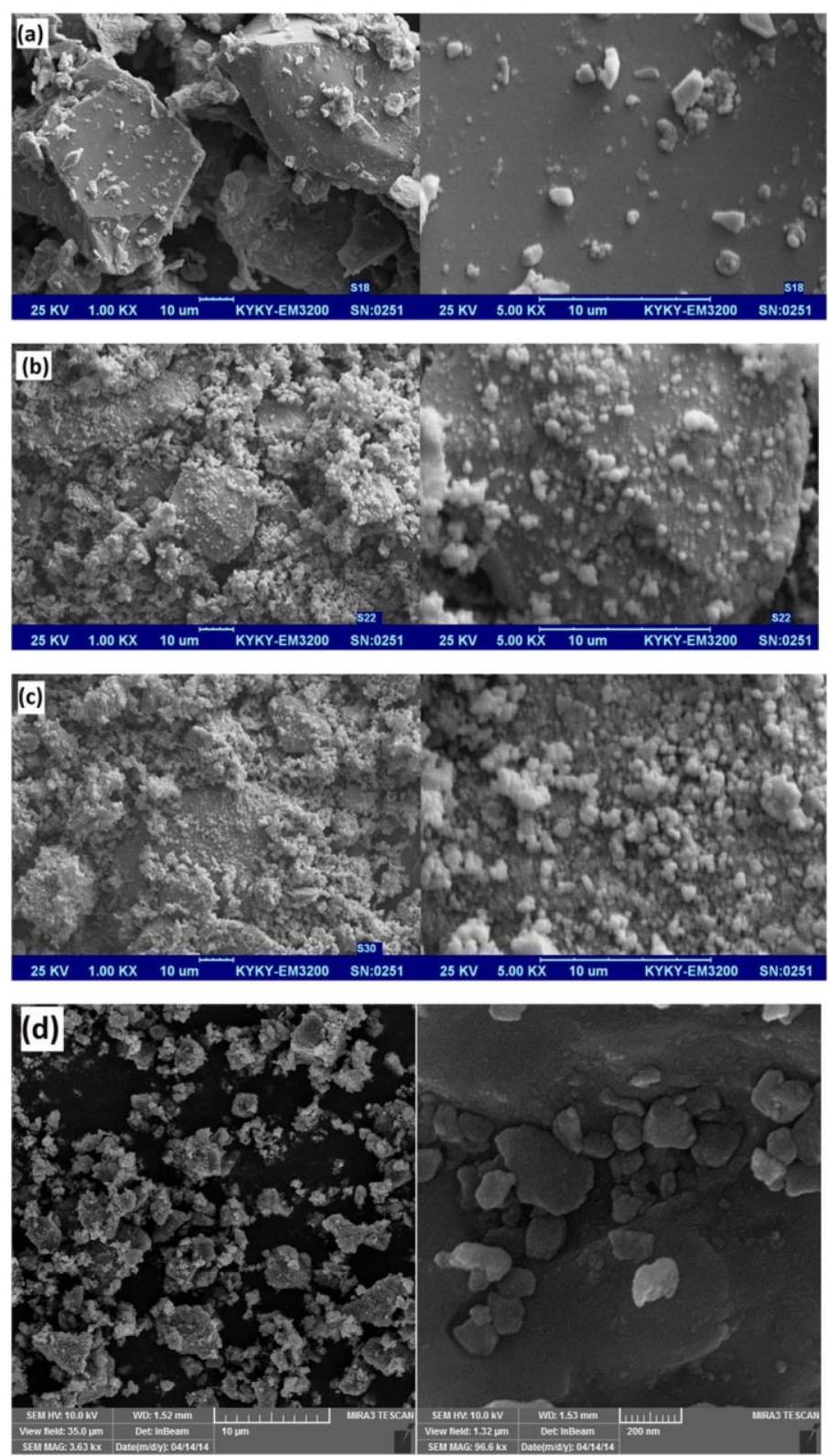

Fig. 5. The morphology of Ti-SiC powder mixture after $1 \mathrm{~h}(\mathrm{a}), 12 \mathrm{~h}$ (b), $24 \mathrm{~h}$ (c), and $36 \mathrm{~h}$ (d) of ball milling process. 

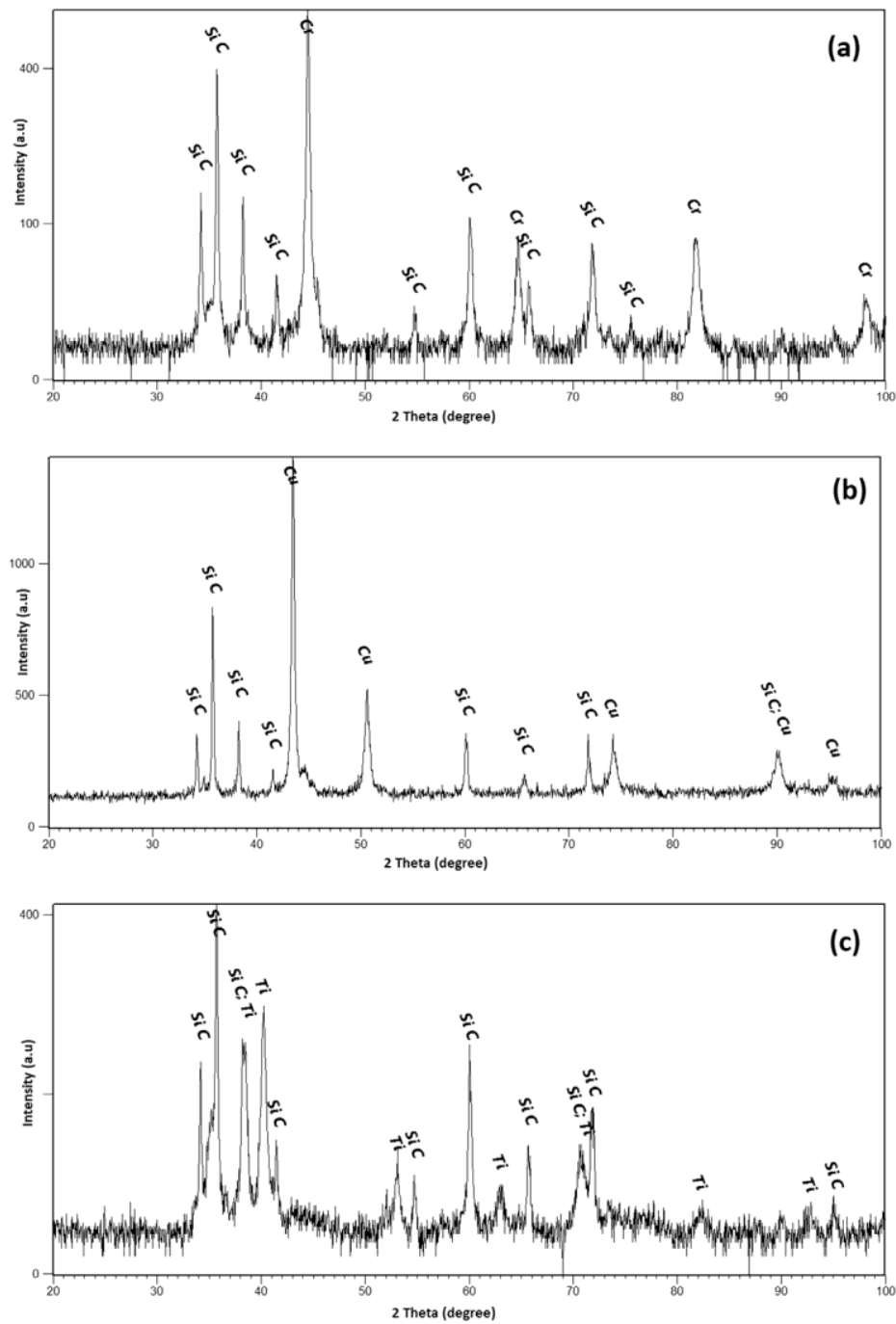

Fig. 6. The X-ray phase analysis of $36 \mathrm{~h}$ ball-milled powders: $\mathrm{Cr}-\mathrm{SiC}(\mathrm{a}), \mathrm{Cu}-\mathrm{SiC}(\mathrm{b})$, and $\mathrm{Ti}-\mathrm{SiC}(\mathrm{c})$

More fine particles were prepared (see Fig. $3 \mathrm{~b}$ ) after $12 \mathrm{~h}$ ball milling in respect to the $1 \mathrm{~h}$ ball-milled powders. In fact, as expected, more fragmentation had occurred, resulting in more formation of submicron $\mathrm{SiC}$ particles. The particles became finer in size after $12 \mathrm{~h}$ and almost the same structure was formed again after a further $12 \mathrm{~h}$ as shown schemat- ically in Fig. 3a. The number and the size of the large SiC particles were reduced after $12 \mathrm{~h}$, while still some of the particles larger than about $10 \mu \mathrm{m}$ could be found (see red-colored rectangles), which shows that prolonged milling might be required for obtaining fine composite parti- cles with almost the same particle size. Fig. 3c shows the morphology of $24 \mathrm{~h}$ milled $\mathrm{Cr}-\mathrm{SiC}$ powders. It was expected that no large sized $\mathrm{SiC}$ par- ticles might be seen after $24 \mathrm{~h}$ ball milling, while as can be seen the full conversion of large $\mathrm{SiC}$ particles to nano- and submicron particles seems not to be possible using the ball-milling parameters of this study. Fig. $3 \mathrm{~d}$ 


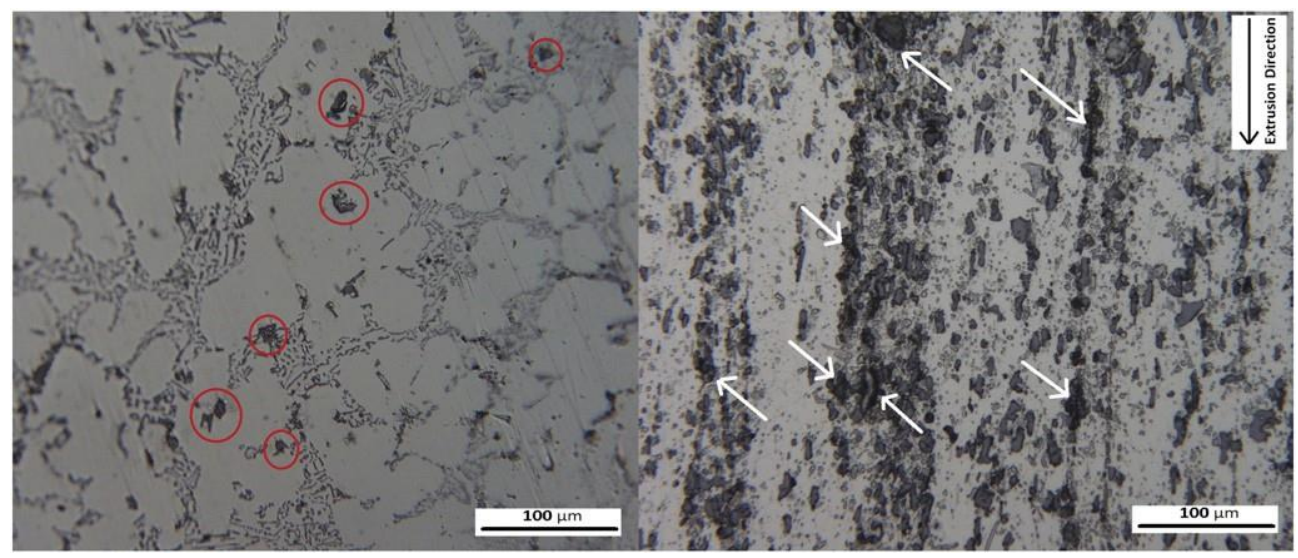

Fig. 7. The optical microscopy images of as-cast sample $S_{1}(a)$, extruded sample $S_{1}(b)$.

shows the FESEM images of $36 \mathrm{~h}$ milled powders. It could be observed that considerable agglomeration occurred after this milling period, the reason of which is not fully clear. It could be seen that some large com- posite particles (even around $100 \mu \mathrm{m}$ ) remained after $36 \mathrm{~h}$. Fig. $3 \mathrm{~d}$ also shows high-magnification morphology of $36 \mathrm{~h}$ ball milled powders (right-hand image). A good distribution of nano- and submicron sized $\mathrm{SiC}$ particles could be seen in this powder mix. The yellow-colored circle marked in the right-hand image shows a submicron-sized particle that formed by adhesion of some nanoparticles. This shows that the pres- ence of the carrier agents could not completely prevent the nanoparticles from re-agglomeration and associated complex structures form forming during milling of the ceramic brittle phase with the ductile metallic phase.

By considering Figs. 4a- $\mathrm{d}$ and $5 \mathrm{a}-\mathrm{d}$, it was concluded that almost the same trend like $\mathrm{Cr}-\mathrm{SiC}$ mixture could be seen for $\mathrm{Cu}-\mathrm{SiC}$ and $\mathrm{Ti}-\mathrm{SiC}$ mix- tures after 1, 12, 24, and $36 \mathrm{~h}$ ball milling. In all of these mixtures, more fine $\mathrm{SiC}$ particles seem to be produced by increasing the milling time. The same structure as schematically shown in Fig. 3a was also formed for all of these mixtures, showing that the type of the carrier agent has no effect on the formed structures and large $\mathrm{SiC}$ particle fracturing. In addition, it was found that the full conversion of large micron sized $\mathrm{SiC}$ particles to nano- and submicron particles was not possible with any of the different carrier agents used. However, Fig. 4d indicates that for the $\mathrm{Cu}$ carrier agent, a spheroidal morphology was obtained after $36 \mathrm{~h}$ milling. The question arises as to why such coarse composite powders were obtained between 24 and $36 \mathrm{~h}$ milling for this mixture. Brun et al. [35] reported that copper powders easily undergo dynamic recovery during ball milling due to their low recovery and recrystallization temperatures, and coarse copper powders were obtained in their study. Therefore, ductility of the copper powders might be increased after $24 \mathrm{~h}$ due to a decrement in the dislocation density as a result of dynamic recovery, leading to the formation of such morphology.

There was a concern whether $36 \mathrm{~h}$ ball milling could lead to a reac- tion between the SiC particles with the metallic carriers or not. Fig. $6 \mathrm{a}-\mathrm{c}$ indicated that no other phases were revealed except the corresponded peaks of $\mathrm{SiC}$ and metallic carriers. This means that $\mathrm{SiC}$ is a suitable choice for use with a carrier agent due to its thermodynamic stability with these agents. Another important result that could be considered from Fig. 6 is the copper and $\mathrm{SiC}$ peaks with a low background thickness and higher intensity than those of the other mixtures, which further leads to consideration that the copper powders undergo dynamic recov- ery after $36 \mathrm{~h}$ milling.

As mentioned, the composite powders were formulated to ease the incorporation of fine fragmented SiC particles into the molten A356 aluminum alloy, and hot extrusion process was then performed after semi- solid stir casting for microstructural improvement. The performance of the carrier agents could be compared using optical OM and FESEM anal- yses. Fig. 7 shows the microstructures of as-cast and extruded samples. $\mathrm{S}_{1}$ is the $\mathrm{Cr}-\mathrm{SiC} 36 \mathrm{~h}$ milled powder. The eutectic structure contains sil- icon phase, which could be observed after stir casting (see Fig. 7a). If just nanoparticles with no agglomeration had been present in the matrix, nothing could be observed after casting under OM analysis. However, red-colored circles in Fig. 7a show the presence of micron sized ceramic phases with a darker color, which their sizes are congruous to what is shown in the red-colored rectangles of Fig. $3 \mathrm{~d}$. Fig. $7 \mathrm{~b}$ shows the microstructure of extruded sample $\mathrm{S}_{1}$. Significant fragmentation of silicon eutectic phase parallel to the extrusion direction is the most impor- tant point that could be understood from this figure. Our previous study [2] indicated that this fragmentation of silicon platelets considerably in- creases the ductility and strength of the A356 aluminum alloy.

Another important point of Fig. 7b (shown with white-colored arrows) is the de- tection of agglomerated composite particles. In fact, the Cr-SiC compos- ite powders with large particle size did not release the nano- and submicronSiCparticle. Based on the required factors of a suitable carrier agent that were mentioned in the Introduction section, it seems that $\mathrm{Cr}$ could not release the fine particles into the molten aluminum even during stirring at $630^{\circ} \mathrm{C}$. This duty of the carrier agent (releasing the ceram- ic particles) is very complex, depended on three factors. First, the temperature of the melt should be high enough for softening of the car- rier agent for a better ceramic releasing; secondly, the particle size of the composite powders is important, as the large composite powders might not be as well unbraided during stirring to release the particles; and thirdly, the nature of reaction between the carrier agent and molten alu- minum is very significant. During an exothermic reaction, the greater amount of heat generated would be expected to aid the reinforcement releasing process, while endothermic reactions negatively affect this process. Therefore, by utilization of smaller composite reinforcement powders and using a carrier agent resulting in an exothermic reaction with the molten aluminum, the method could be more successful. 


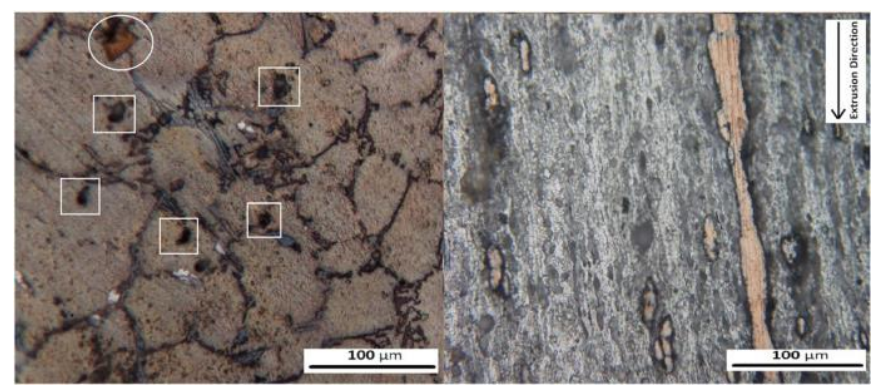

Fig. 8. The optical microscopy images of as-cast sample $S_{2}$ (a), extruded sample $S_{2}(b)$.
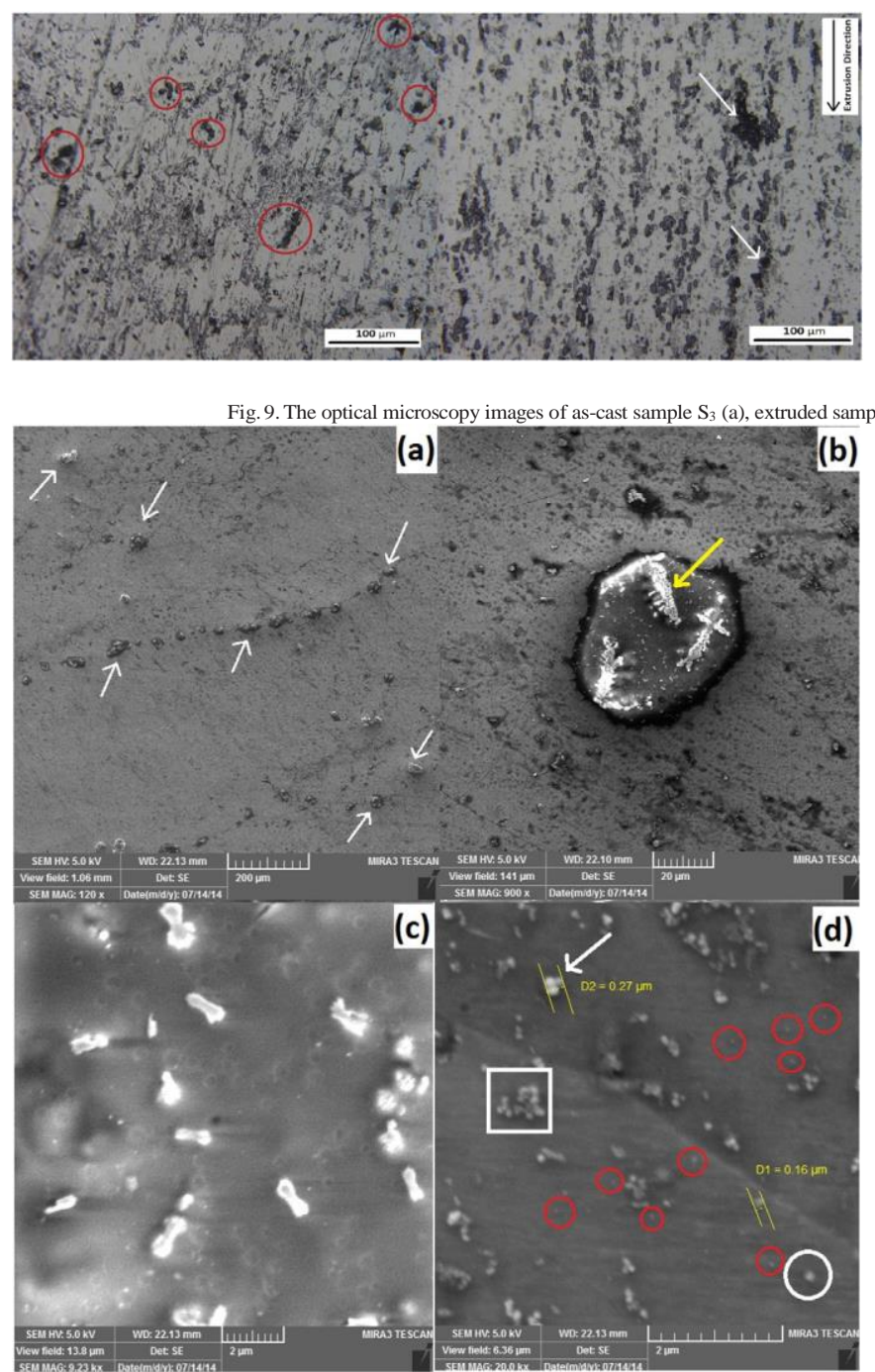

Fig. 10. The FESEM images of extruded sample $S_{1}$ (a) low-magnification, (b) magnified image $a$, (c) magnified image $b$, and (d) magnified image a from another area. 


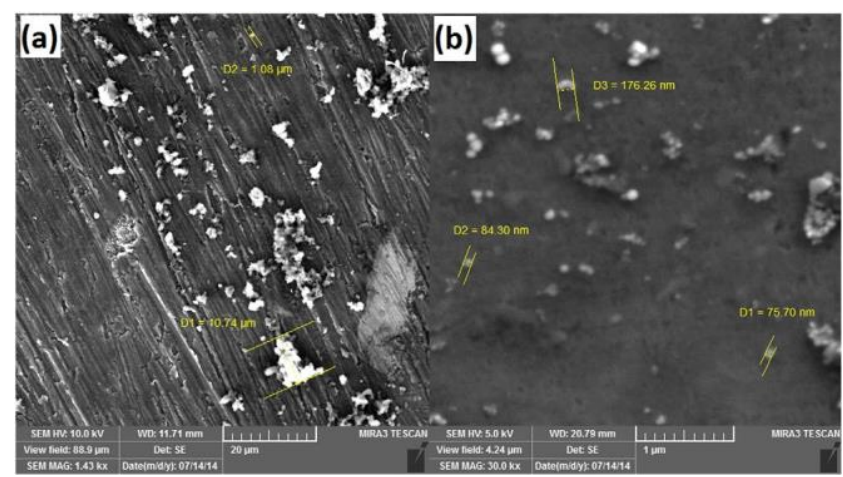

Fig. 11. The FESEM images of extruded sample $\mathrm{S}_{2}$ (a) low-magnification, and (b) magnified image a.

Fig. 8 shows the $\mathrm{OM}$ images of as cast and extruded sample $\mathrm{S}_{2}$ con- tains $\mathrm{Cu}-\mathrm{SiC}$ powders. The presence of dark ceramic phases (marked in white-colored squares) and the detection of an orange colored phase that could be related to the copper (marked in white-colored circle) are the most important points of Fig. 8a. Fig. 8b shows the micro- structure of sample $S_{2}$ after extrusion process. Considerable presence of the copper metallic phase (orange-colored) covered by a dark layer of $\mathrm{SiC}$ fine particles and its deformation toward the extrusion direction backs the idea of core-shell structure formation as suggested by Xu et al. [34]. A dark layer could be seen around the orange-colored phases in Fig. $8 \mathrm{~b}$, suggesting that a core (carrier agent)-shell (nano- and submi- cron SiC particles) structure could be formed after ball milling of these two phases.

Fig. $4 \mathrm{~d}$ showed that $36 \mathrm{~h}$ milled $\mathrm{Cu}-\mathrm{SiC}$ powders contain large parti- cles. Rajan and co-workers [36] also reported the formation of $\mathrm{CuAl}_{2}$ phase with an endothermic nature reaction between copper coating on reinforcement phase with the aluminum melt. It is believed that these two subjects caused the considerable presence of large-sized ag- glomerated $\mathrm{Cu}-\mathrm{SiC}$ powders after casting and extrusion.

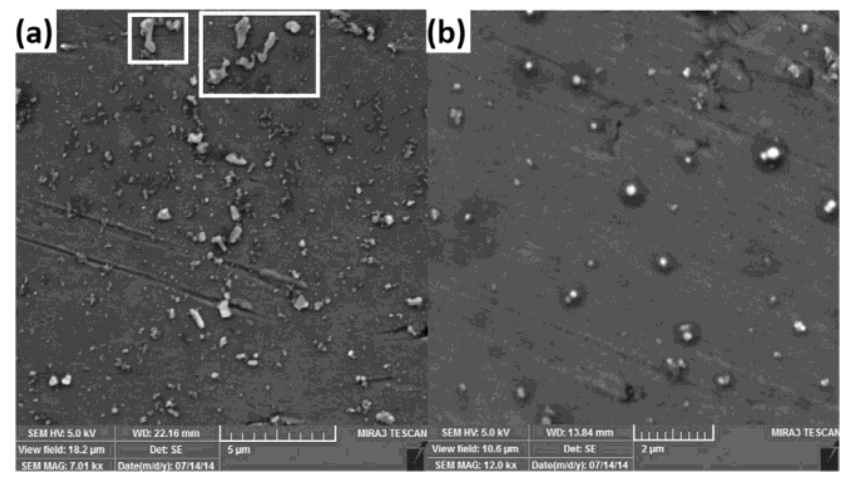

Fig. 12. The FESEM images of extruded sample $S_{3}$ (a) low-magnification, and (b) magnified image a.

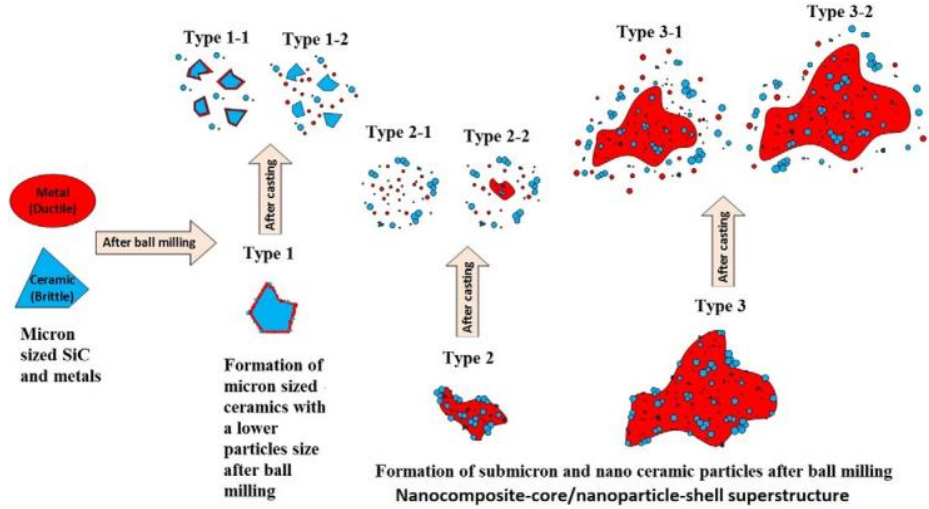

Fig. 13. Schematic that proposes the various kinds of structures that might be obtained after ball milling of a coarse ceramic powder with a metallic carrier agent.

Fig. 9 is related to the microstructure of sample $S_{3}$ after casting (Fig. 9a) and extrusion (Fig. 9b). By comparing Figs. 7a, 8a, and 9a, it was obtained that more dark-colored phases with a lower particle size and a semi-ideal distribution was revealed for the sample $S_{3}$ (Fig. 9a). As very little particle rejection was equally observed for all the samples during stirring, it seems that the more presence of the ceramics in the 
matrix of sample $\mathrm{S}_{3}$ might be related to their lower agglomeration be- fore and during casting. Fig. 5d shows the more formation of fine composite particles with lower agglomeration compared with Figs. $3 \mathrm{~d}$ and $4 \mathrm{~d}$, meaning that more fine Ti-SiC particles were entered into the melt. In addition, based on the literature [37-40], irrespective of the

reaction between $\mathrm{Cu}$ and $\mathrm{Al}$ with an endothermic nature, the Gibbs free energy for formation of $\mathrm{Al}_{3} \mathrm{Ti}$ at $630{ }^{\circ} \mathrm{C}$ is much higher than (more negative) those of different kinds of Al-Cr binary intermetallic compounds such $\mathrm{Al}_{4} \mathrm{Cr}$. Therefore, exothermic reactions with a higher intensity might be taken place between the Ti powders and aluminum melt, lead- ing to the entrance of higher amount of heat during stirring for the sam- ple $\mathrm{S}_{3}$ than the other samples. Fig. 9b also shows the lower detection of dark phases compared with the other samples after extrusion.

The engulfment or pushing of the fine particles could be understood from these results. Fig. 10a shows the low-magnification microstructure of sample $S_{1}$ after extrusion process. The presence of some large com- posite powders (shown by white-colored arrows), which were aligned parallel the extrusion direction, is clearly visible. Fig. 10b shows one of these $\mathrm{Cr}-\mathrm{SiC}$ particles in a higher magnification, in which an interesting phenomenon was taken place. It could be observed that some phases with a dendrite-like morphology were formed on the composite powder, which EDAX analysis confirmed the strong trace of $\mathrm{Cr}$ and $\mathrm{Al}$ in these areas. These phases (shown by a yellow-colored arrow) are Al$\mathrm{Cr}$ intermetallic phases with a composition close to $\mathrm{Al}_{4} \mathrm{Cr}$ intermetallic compound. This result is important from the reaction point of view, which shows that the negative effect of particle size on release of the composite reinforcement. In terms of reinforcement releasing the effect of fine particles is more dominant than exothermic reaction occurrence within the carrier metals investigated. Fig. 10d shows a very important result from the behavior of Cr carrier agent, in that the nano- (below $100 \mathrm{~nm}$ ) and submicron (100-300 nm) SiC particles could enter into the melt in various places and that a direct contact between such parti- cles was obtained within the aluminum alloy matrix. In fact, this result indicated that the fine $\mathrm{Cr}-\mathrm{SiC}$ powders shown in Fig. $3 \mathrm{~d}$ were able to re- lease the nano- and submicron particles into the melt, showing that this method could be successful if the particle size of the composite powders is low. Four areas were marked and highlighted in Fig. 10d. The first, indicated in a white-colored circle that shows a single submicron parti- cle in the range of 100-200 $\mathrm{nm}$. The second, indicated in red-colored cir- cles that shows the presence of single nanoparticles below $100 \mathrm{~nm}$. The third, indicated in a white-colored square that shows a cluster of submi- cron particles, and finally a white-colored arrow points to agglomera- tion of three submicron particles. In fact, it could be concluded that single nano- and submicron particles could be distributed in the matrix using the carrier agent method, and agglomerated submicron particles (after ball-milling) with strong bonding were also incorporated into the melt. The last important point, shown in the white-colored square, is the formation of submicron SiC clusters with no or weak bonding. In fact, these types of clusters were formed during solidification. Ferguson et al. [32] reported that the ceramics with a particle size between $100 \mathrm{~nm}$ to $10 \mu \mathrm{m}$ is highly prone to be pushed by the solidification front in contrast with the nanoparticles and micron-sized particles above $10 \mu \mathrm{m}$ size. In fact, submicron particles have Stokesian motion be- havior. Fig. 10d shows that no such clusters were revealed for nanoparticles.

Fig. 11 shows the FESEM characterization of extruded sample $\mathrm{S}_{2}$, in which $\mathrm{Cu}-\mathrm{SiC}$ composite powders were incorporated into the molten melt. Fig. 11a shows the considerable presence of micron-sized compos- ite particles that were not released, and did not distribute the fine ceramic particles in most places. It could be seen that the extrusion process was not effective when unreleased composite particles were present in the as-cast microstructure. The extrusion process might sep- arate the composite particles depended on the bonding between the SiC particles and the carrier agents, while the separated composite particle boundaries in this case could areas act as weak points in terms of the composite mechanical properties.

A finer FESEM microstructure was obtained for the sample $\mathrm{S}_{3}$. Fig. 12a shows the incorporation of fine SiC particles into the semisolid molten metal. The lower detection of large micron-sized particles in respect to the previous samples and the more presence of nano- and submicron particles with a better distribution of fine particles are the two main differences between the sample $\mathrm{S}_{3}$ and the previous sam- ples. EDAX analysis confirmed that the phases shown by white-colored rectangles in Fig. $12 \mathrm{a}$ mainly contain Al and Ti elements, showing that they are Al-Ti intermetallic compounds with a chemical composition close to $\mathrm{Al}_{3} \mathrm{Ti}$ intermetallic phase, which extrusion process might cause their severe fragmentation after casting because our previous study indicated that such intermetallics have considerable large size with edge-like morphology. Both Fig. 12a and b confirmed that irrespec- tive of suitable distribution and entrance of fine particles for the sample $\mathrm{S}_{3}$, the presence and formation of agglomerated particles as well as solidification-induced clusters is inevitable even for this sample. Fig. $12 \mathrm{~b}$ shows that a relatively better distribution was obtained for the sample $\mathrm{S}_{3}$, while due to the incomplete releasing of fine particles during stirring, incomplete conversion of micron to nanosized ceramic particles, and formation of large composite powders after ball milling, the achievement to the fabrication of an ideal AMNC seems not to be easy using this method.

In order to show the concept of carrier agent, micron to nanosized particle conversion, and the structures that were formed in this study after casting, a schematic was designed and prepared. Fig. 13 indicates that due to ball milling of a ductile metal (carrier agent) with a brittle ceramic (SiC), five types of composite structures could be prepared. The first type (type 1) is the micron sized SiC particles with a lower particle size than that of the as-received SiC particles. These smaller parti- cles have a metallic layer on their surfaces. For example, the redcolored rectangles in Fig. 3b showed such composite type. As could be observed, two types 1-1 and 1-2 could be prepared from the first type after casting process. A layer of copper on the SiC particles which exhibits the formation of type 1-1 was previously shown in our previous studies [2,26]. It is believed that the nature of reaction between the carrier agent and the molten metal caused the separation of the car- rier agent and its entrance into the molten metal. It could be suggested that endothermic reactions or very weak exothermic reactions caused the formation of type 1-1 (2-1, 3-1, and 4-1), while exothermic reac-

tions may lead to formation of type 1-2 (2-2, 3-2, and 4-2). Therefore, based on the high Gibbs free energy for the formation reaction of $\mathrm{Al}_{3} \mathrm{Ti}$ at $630{ }^{\circ} \mathrm{C}$, type 1-2 might have occurred for the sample $\mathrm{S}_{3}$, as the trace of Ti could not be found around the micron-sized SiC particles using EDAX analysis. Figs. 4-6 clearly showed the formation of types 2 and 3 after ball milling process. The difference between types 2 and 3 is the composite particle size. It could be observed that low-sized composite particles (type 2) have a higher chance for releasing the fine ceramic particles during stirring. Xu et al. [34] suggested that such types (2 and 3) could be named as nanocomposite-core/nanoparticle-shell superstructure. It could be observed that agglomerated nano- or submi- cron particles on the composite surface would be entered into the melt with no morphological change. All these superstructures were re- vealed in Figs. 10-12. It seems that both types 3-1 and 3-2 are highly harmful for the mechanical properties of the final composites.

The relative densities of the samples before and after extrusion are given in Table 3. It could be seen that sample $\mathrm{S}_{2}$ has the minimum rela- tive density, while sample $S_{3}$ has a maximum relative density. Based on the characteristics of the samples, it seems that the formation of types 2 and 3 superstructures (see Fig. 13) is highly responsible for the entrance of air gaps and porosities into the composites. Fig. 5d showed a spheroi- dal like morphology that contains air gaps and such structures are po- tential for reduction of the relative density of the final composites. It could be 
observed that hot extrusion process could not highly remove the pores from the as-cast samples. Fig. 10b shows composite particles that seems to have sintered during casting and for which the extrusion process could not successfully remove the resultant pores.

The tensile properties and hardness of composites were obtained and reported in Table 4. It can be seen that the methods performed in this study could not be valuable if copper and chromium were used as the carrier agents. Microstructural characterizations indicated that why these two metals are not potential for this purpose. In fact, 8 and $13 \%$ increases in the UTS values of the samples $S_{2}$ and $S_{1}$, respectively, are not valuable, while very low ductilities were obtained for them. However, the hardness of both the mentioned samples is much higher than that of A356 aluminum alloy, showing that the unloosed compos- ite particles have poor tensile properties, while they were much effec- tive for increasing the composites hardness. On the other hand, more than about $45 \%$ increases in the YS and UTS values and 100\% increase for the hardness were obtained for the sample $\mathrm{S}_{3}$ and its ductility $(8.5 \%)$ is also suitable, showing that Ti could be considered as a suitable carrier agent of the fine particles. The extrusion process overall slightly enhanced the hardness of the samples mainly due to the removal of porosity.

Titanium was found to be a suitable carrier agent and further studies on Ti might therefore lead to the development of improved AMNCs using this method. Lower sized composite powders after ball milling could be obtained by optimization of ball milling parameters and by changing the ratio of $\mathrm{Ti}$ to $\mathrm{SiC}$ mass percent. In addition, by using a cryomilling process or lower Ti particle size, more valuable mechanical properties might also be obtained.

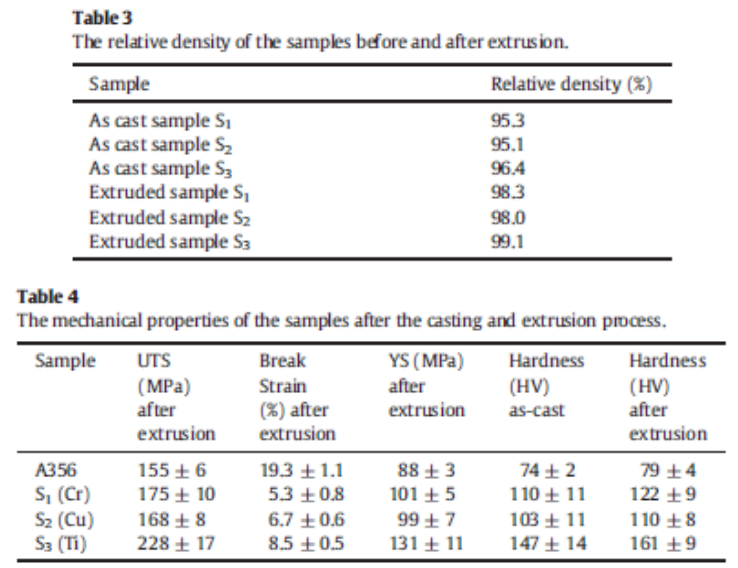

\section{Conclusions}

The idea of using a carrier agent was applied for incorporation of fine ceramic particles into the molten aluminum. SiC encapsulated with carrier agents of $\mathrm{Cr}, \mathrm{Cu}$, and $\mathrm{Ti}$ metallic powders were utilized for this. In- stead of using nanoparticles, coarse $\mathrm{SiC}$ particles were used based on the idea that they could be fragmented by increasing the milling time to form $\mathrm{SiC}$ nanoparticles. The milled powders were then incorporated into the semi-solid melt of A356 alloy and the final composites were ex- truded at $500{ }^{\circ} \mathrm{C}$. From the experimental results, the following conclusions could be drawn:

1. The particle size of the coarse $\mathrm{SiC}$ powders was decreased by increas- ing the milling time. However, fine micron $\mathrm{SiC}$ particles around $10-20$ $\mu \mathrm{m}$ were detected even after $36 \mathrm{~h}$ milling, indicating that not all of the large particles converted to submicron and nanoparticles at prolonged milling time.

2. The presence of nanoparticles, submicron particles, and fine micron particles in the matrix of A356 alloy showed that multimodal sized $\mathrm{SiC}$ particles in the range of $50 \mathrm{~nm}$ to $20 \mu \mathrm{m}$ were produced during milling with metallic carrier agents.

3. XRD results indicated that the $\mathrm{SiC}$ particles are stable with the $\mathrm{Cr}, \mathrm{Cu}$, and $\mathrm{Ti}$ carrier agents from the reaction point of view after $36 \mathrm{~h}$ ball milling process, showing that the idea of using a carrier agent could be applied with the $\mathrm{SiC}$ reinforcing phase.

4. It was found that extrusion process could not alter the distribution of nanoparticles or submicron particles. However, a significant fragmentation of silicon platelets was observed after extrusion, leading to a complete change in the composite microstructures.

5. It was found that the method of using a carrier agent could be suc- cessful if the carrier could release the ceramic particles during stirring. The melting temperature of the carrier, the composite powder particle size, the stirring time and temperature, the viscosity of the melt, and the reaction tendency of the carrier with the melt affect the success of this method. It was also found that the Ti carrier agent was more successful than the $\mathrm{Cu}$ and $\mathrm{Cr}$ agents regarding the formation of a composite with higher amount of fine ceramic parti- cles with a more ideal ceramic distribution.

6. Even the complete release of ceramic particles by the carrier agent could not guarantee the formation of AMNCs with ideal ceramic distribution due to segregation and agglomeration during stirring and solidification of nano- and in particular for sub-micron sized SiC particles.

7. More than $45 \%$ and $100 \%$ increases were obtained for the strength and hardness of a composite contains Ti carrier agent, while it was found that $\mathrm{Cr}$ and $\mathrm{Cu}$ are not suitable for increasing the mechanical properties of the final composites. A maximum UTS of $228 \mathrm{MPa}$ and YS of $131 \mathrm{MPa}$ were obtained for sample $\mathrm{S}_{3}$ and a maximum break strain of $8.5 \%$ was recorded. 


\section{References}

[1] M. Javidani, D. Larouche, Application of cast Al-Si alloys in internal combustion en- gine components, Int. Mater. Rev. 59 (2014) 132-158

[2] N.B. Khosroshahi, R.T. Mousavian, R.A. Khosroshahi, D. Brabazon, Mechanical prop- erties of rolled A356 based composites reinforced by Cu-coated bimodal ceramic particles, Mater. Des. 83 (2015) 678-688.

[3] S. Tutunchilar, M. Haghpanahi, M.B. Givi, P. Asadi, P. Bahemmat, Simulation of mate- rial flow in friction stir processing of a cast Al-Si alloy, Mater. Des. 40 (2012) 415426.

[4] M. Zuo, D. Zhao, X. Teng, H. Geng, Z. Zhang, Effect of P and Sr complex modification on Si phase in hypereutectic Al-30Si alloys, Mater. Des. 47 (2013) $857-864$.

[5] Z. Ma, A. Samuel, H. Doty, S. Valtierra, F. Samuel, Effect of Fe content on the fracture behaviour of Al-Si-Cu cast alloys, Mater. Des. 57 (2014) $366-373$.

[6] L. Bolzoni, M. Nowak, N.H. Babu, Grain refinement of Al-Si alloys by Nb-B inocula- tion. Part II: application to commercial alloys, Mater. Des. 66 (2015) 376-383.

[7] A.F. Boostani, S. Tahamtan, Z. Jiang, D. Wei, S. Yazdani, R.A. Khosroshahi, et al., En- hanced tensile properties of aluminium matrix composites reinforced with graphene encapsulated SiC nanoparticles, Compos. A: Appl. Sci. Manuf. 68 (2015) 155-163.

[8] L.-J. Zhang, F. Qiu, J.-G. Wang, Q.-C. Jiang, High strength and good ductility at elevat- ed temperature of nano-SiC p/Al2014 composites fabricated by semi-solid stir cast- ing combined with hot extrusion, Mater. Sci. Eng. A 626 (2015) 338-341.

[9] S. Tahamtan, A. Halvaee, M. Emamy, Z. Jiang, A.F. Boostani, Exploiting superior ten- sile properties of a novel network-structure AlA206 matrix composite by hybridiz- ing micron-sized $\mathrm{Al} 3 \mathrm{Ti}$ with $\mathrm{Al}_{2} \mathrm{O}_{3}$ nanoparticulates, Mater. Sci. Eng. A 619 (2014) 190-198.

[10] Y. Yang, J. Lan, X. Li, Study on bulk aluminum matrix nano-composite fabricated by ultrasonic dispersion of nano-sized SiC particles in molten aluminum alloy, Mater. Sci. Eng. A 380 (2004) 378-383.

[11] R. Immanuel, S. Panigrahi, Influence of cryorolling on microstructure and mechani- cal properties of a cast hypoeutectic Al-Si alloy, Mater. Sci. Eng. A 640 (2015) 424435 .

[12] K. Kalaiselvan, N. Murugan, S. Parameswaran, Production and characterization of AA6061-B4C stir cast composite, Mater. Des. 32 (2011) 4004-4009.

[13] S.K. Ghosh, P. Saha, Crack and wear behavior of SiC particulate reinforced aluminium based metal matrix composite fabricated by direct metal laser sintering process, Mater. Des. 32 (2011) $139-145$

[14] O. El-Kady, A. Fathy, Effect of SiC particle size on the physical and mechanical prop- erties of extruded Al matrix nanocomposites, Mater. Des. 54 (2014) $348-353$

[15] S. Suresh, N.S.V. Moorthi, S. Vettivel, N. Selvakumar, Mechanical behavior and wear prediction of stir cast Al-TiB ${ }_{2}$ composites using response surface methodology, Mater. Des. 59 (2014) 383-396.

[16] R. Zheng, H. Yang, T. Liu, K. Ameyama, C. Ma, Microstructure and mechanical prop- erties of aluminum alloy matrix composites reinforced with Fe-based metallic glass particles, Mater. Des. 53 (2014) 512-518.

[17] B.A. Kumar, N. Murugan, Metallurgical and mechanical characterization of stir cast AA6061-T6-AlN p composite, Mater. Des. 40 (2012) 52-58

[18] D. Kumar, R. Narayanasamy, C. Loganathan, Effect of glass and SiC in aluminum ma- trix on workability and strain hardening behavior of powder metallurgy hybrid composites, Mater. Des. 34 (2012) 120-136.

[19] M. Roshan, T.R. Mousavian, H. Ebrahimkhani, A. Mosleh, Fabrication of Al-based composites reinforced with $\mathrm{Al}_{2} \mathrm{O}_{3}-\mathrm{Tib}_{2}$ ceramic composite particulates using vortex-casting method, Journal of Mining and Metallurgy, Section B: Metallurgy. 49 (2013) 299-305.

[20] R.T. Mousavian, S. Damadi, R.A. Khosroshahi, D. Brabazon, M. Mohammadpour, A comparison study of applying metallic coating on SiC particles for manufacturing of cast aluminum matrix composites, The International Journal of Advanced Manufacturing Technology. (2015) 1-12.

[21] S. Kumar, R.S. Panwar, O. Pandey, Effect of dual reinforced ceramic particles on high temperature tribological properties of aluminum composites, Ceram. Int. 39 (2013) 63336342.

[22] D. Zhou, F. Qiu, Q. Jiang, The Nano-sized TiC particle reinforced Al-Cu matrix com- posite with superior tensile ductility, Mater. Sci. Eng. A 622 (2015) 189-193.

[23] J. Aguilar, M. Fehlbier, A. Ludwig, A. Bührig-Polaczek, P. Sahm, Non-equilibrium globular microstructure suitable for semisolid casting of light metal alloys by rapid slug cooling technology (RSCT), Mater. Sci. Eng. A 375 (2004) 651-655.

[24] S. Nafisi, R. Ghomashchi, Effect of stirring on solidification pattern and alloy distribu- tion during semi-solid-metal casting, Mater. Sci. Eng. A 437 (2006) $388-395$.

[25] N.B. Khosroshahi, R.A. Khosroshahi, R.T. Mousavian, D. Brabazon, Effect of electroless coating parameters and ceramic particle size on fabrication of a uniform Ni-P coat- ing on SiC particles, Ceram. Int. 40 (2014) 12149-12159.

[26] N. Beigi Khosroshahi, R. Azari Khosroshahi, R. Taherzadeh Mousavian, D. Brabazon, Electroless deposition (ED) of copper coating on micron-sized SiC particles, Surf. Eng. 30 (2014) 747-751.

[27] M. Mohammadpour, R.A. Khosroshahi, R.T. Mousavian, D. Brabazon, A novel method for incorporation of micron-sized SiC particles into molten pure aluminum utilizing a Co coating, Metall. Mater. Trans. B 46 (2015) 12-19.

[28] H. Noori, R.T. Mousavian, R.A. Khosroshahi, D. Brabazon, S. Damadi, Effect of SiC par- ticle morphology on Co-P electroless coating characteristics, Surf. Eng. (2015), http://dx.doi.org/10.1179/1743294415Y.0000000035.

[29] H. Su, W.L. Gao, H. Zhang, H.B. Liu, J. Lu, Z. Lu, Study on preparation of large sized nanoparticle reinforced aluminium matrix composite by solid-liquid mixed casting process, Mater. Sci. Technol. 28 (2012) 178-183.

[30] B. Schultz, J. Ferguson, P. Rohatgi, Microstructure and hardness of $\mathrm{Al}_{2} \mathrm{O}_{3}$ nanoparticle reinforced Al-Mg composites fabricated by reactive wetting and stir mixing, Mater. Sci. Eng. A 530 (2011) 87-97.

[31] J. Ferguson, B.F. Schultz, P.K. Rohatgi, C.-S. Kim, Impact of Brownian motion on the particle settling in molten metals, Met. Mater. Int. 20 (2014) 747-755.

[32] J. Ferguson, G. Kaptay, B.F. Schultz, P.K. Rohatgi, K. Cho, C.-S. Kim, Brownian motion effects on particle pushing and engulfment during solidification in metal-matrix composites, Metall. Mater. Trans. A 45 (2014) 4635-4645.

[33] M. Dehnavi, B. Niroumand, F. Ashrafizadeh, P. Rohatgi, Effects of continuous and dis- continuous ultrasonic treatments on mechanical properties and microstructural characteristics of cast Al413-SiC np nanocomposite, Mater. Sci. Eng. A 617 (2014) 73-83.

[34] J. Xu, L. Chen, H. Choi, H. Konish, X. Li, Assembly of metals and nanoparticles into novel nanocomposite superstructures, Sci. Report. 3 (2013).

[35] P. Le Brun, E. Gaffet, L. Froyen, L. Delaey, Structure and properties of $\mathrm{Cu}, \mathrm{Ni}$ and $\mathrm{Fe}$ powders milled in a planetary ball mill, Scr. Met. Mater. 26 (1992) $1743-1748$

[36] T. Rajan, R. Pillai, B. Pai, Reinforcement coatings and interfaces in aluminium metal matrix composites, J. Mater. Sci. 33 (1998) $3491-3503$.

[37] N. Yue, L. Lu, M. Lai, Application of thermodynamic calculation in the in-situ process of Al/TiB 2, Compos. Struct. 47 (1999) 691-694.

[38] B.B. Singh, M. Balasubramanian, Processing and properties of copper-coated carbon fibre reinforced aluminium alloy composites, J. Mater. Process. Technol. 209 (2009) $2104-$ 2110.

[39] Y. Liang, C. Guo, C. Li, Z. Du, Thermodynamic modeling of the Al-Cr system, J. Alloys Compd. 460 (2008) $314-319$.

[40] J. Murray, The Al-Cr (aluminum-chromium) system, Journal of Phase Equilibria 19 (1998) 367-375. 